\title{
O SOFRIMENTO DO CORPO E DA PSIQUE SOB A DOMINAÇÃO SOCIAL ${ }^{1}$
}

\author{
Dulce Regina dos Santos Pedrossian
}

Resumo: Este texto é resultante da pesquisa teórica denominada $A$ ideologia da racionalidade tecnológica, o narcisismo e a melancolia: marcas do sofrimento, que teve como objetivo verificar a relação entre o narcisismo, a melancolia e a ideologia da racionalidade tecnológica por meio de alguns conceitos mediadores, tais como indústria cultural e fenômenos de massa, que tendem a reproduzir a dominação social nos diversos âmbitos da vida do indivíduo na sociedade atual. Para sua elaboração, utilizamos escritos de autores e estudiosos da teoria crítica da sociedade e da teoria freudiana.

Palavras-chave: Teoria crítica da sociedade. Dominação social. Ideologia da racionalidade tecnológica.

Quando Adorno (1955/1986) se refere à psicologia social analiticamente orientada e procura compreender a relação existente entre indivíduo e sociedade em função não apenas dos comportamentos irracionais da coletividade, como, também da redução dos indivíduos a comportamentos adaptativos e voltados para o lucro, evidencia que não há uma relação harmônica entre a psicologia social analiticamente orientada e a teoria freudiana. No entanto, Adorno concebe o pensamento freudiano como importante, sendo que, em escritos de Freud, encontra possibilidade de organizar a relação existente entre a gênese das questões psíquicas e a gênese das questões sociais, ou seja, de compreender que o fenômeno social se estende ao psíquico e, esse, igualmente, estende-se ao social. Assim, no momento em que adotamos a teoria freudiana, não promovemos uma fratura entre a psicologia social e a psicanálise, pois,

1 Trabalho decorrente da tese de doutorado PUCSP (2005). Apoio Institucional:CAPES/PICDT 
para Freud (1921/1976a), a psicologia individual é, sobretudo, psicologia social. Mais ainda, não propomos uma separação entre teoria e prática psicanalítica - a teoria de Freud foi baseada, principalmente, na clínica, não se reduzindo a ela.

Tendo em vista as duas teorias de explicação dos fenômenos - a teoria crítica da sociedade e a teoria freudiana - não pretendemos, neste estudo, integrar as duas concepções teóricas, mas confrontá-las, e, com isso, as relações de tensão entre elas necessitam ser analisadas com suficiente amplitude, advertindo, de acordo com Adorno (1955/1986), para a particularidade do objeto de estudo. Esse enunciado demarca, portanto, nossa reflexão no decorrer deste trabalho, sendo que a psicologia social analiticamente orientada está, de forma implícita ou explícita, igualmente presente na análise, pois, para Adorno (1955/1986), a cisão entre indivíduo e sociedade impõe a necessidade de uma psicologia social que não só organize seus preceitos com uma teoria da sociedade, mas, também, utilize uma orientação psicanalítica.

O mal-estar na cultura, proveniente do ajustamento acirrado do indivíduo ao meio social e do declínio da própria individuação, pode ser explicado pelo fato de a ideologia manifestar-se na própria sociedade real (Adorno, 1951/1998a). Nesse texto de 1951, Adorno já visualizava que a sociedade organizada, de acordo com o modelo do ato de troca, veste uma capa de normalização da ideologia com o intento de encobrir o potencial dialético do movimento social.

Quanto mais a sociedade progride, mais se apresenta racionalizada, convertendo-se em espaço de domínio dos indivíduos entre si, sobre a natureza e sobre a cultura, e não apenas "...a racionalidade ligada à dominação está ela própria na base do sofrimento" (Horkheimer \& Adorno, 1947/1985, p. 159), como, também, algo específico da ideologia da racionalidade tecnológica é o seu caráter formal de dominação. Os conceitos de dominação e de ideologia da racionalidade tecnológica estão, portanto, intimamente relacionados e, com isso, os termos ideologia, racionalidade tecnológica, racionalidade técnica e razão técnica, presentes nos escritos dos frankfurtianos estudados, conservam a dominação social.

A síntese entre o particular e o todo não é possível, pelo menos, no momento em que a liberdade ainda é inexistente (Crochík, 1990). A totalidade diz respeito à sociedade e legitima o universal ainda que nem sempre e nem para todos. A concepção de universal traz consigo elementos que todos os homens podem desenvolver, como a linguagem e o pensamento, que podem estar comprometidos com a liberdade e/ou com a dominação.

Marcuse (1941/1999a, p.76) evidencia a eliminação da"racionalidade individualista" e do indivíduo econômico livre, e sob o efeito do aparato, sendo que esse termo indica dispositivos, instituições e organizações da indústria em sua condição social dominante, “...a racionalidade individua- 
lista se viu transformada em racionalidade tecnológica" (p.77). No entanto, para o autor:

A individualidade... não desapareceu. $O$ sujeito econômico livre, em vez disso, tornou-se objeto de organização e coordenação em larga escala, e o avanço individual se transformou em eficiência padronizada. Esta última se caracteriza pelo fato de que o desempenho individual é motivado, guiado e medido por padrões externos ao indivíduo, padrões que dizem respeito a tarefas e funções predeterminadas. (Marcuse, 1941/1999a, p. 78)

Na relação sujeito-objeto, a separação torna-se ideológica, ao ser firmada sem mediação. A existência individual, que necessita ser considerada, encontra-se encoberta diante da tendência objetiva. Com o enfraquecimento da capacidade de pensar sobre si mesmo e sobre o que faz, as atitudes particulares são regidas pela lógica da eficiência estandardizada, como se ainda pudessem atuar na qualidade de indivíduos e algo procedesse da sua atuação.

O desempenho do indivíduo, na sociedade capitalista, é guiado por normas externas, ou melhor, a liberdade individual está limitada à escolha dos meios mais adequados para atingir uma meta que ele não delimitou de forma direta. Nesse ponto, Marcuse (1964/1967), em um outro texto, tem algo a nos acrescer:

Essa absorção da ideologia pela realidade não significa, contudo, o "fim da ideologia." Pelo contrário, em sentido específico, a cultura industrial avançada é mais ideológica do que sua predecessora, visto que, atualmente, a ideologia está no próprio processo de produção. Esta proposição revela, de forma provocadora, os aspectos políticos da racionalidade tecnológica prevalecente. $\mathrm{O}$ aparato produtivo e as mercadorias e serviços que ele produz "vendem" ou impõem o sistema social como um todo... Os produtos doutrinam e manipulam; promovem uma falsa consciência que é imune à sua falsidade. $E$, ao ficarem esses produtos benéficos à disposição de maior número de indivíduos e de classes sociais, a doutrinação que eles portam deixa de ser publicidade; torna-se um estilo de vida. (pp.31-32, itálico do autor)

O fato de a ideologia manifestar-se na realidade social não implica o fim da ideologia. As contradições sociais continuam a existir, possibilitando ao indivíduo - apesar da falta de movimento de sua consciência - perceber que a racionalidade da técnica se encontra engendrada no processo de produção. Há necessidade de crítica permanente para que o esclarecimento, como autoconscientização, exceda o caráter afirmativo da cultura que administra a produção e o consumo.

Na representação da totalidade social injusta desaparece toda a responsabilidade do pensamento. A falsa consciência trata-se de algo cientificamente ajustado à sociedade atual. Se, de um lado, podemos considerar 
os fenômenos de massa como um processo secundário - "Os horrores que hoje ameaçam o mundo não são produzidos pelas massas, mas por tudo aquilo e por todos aqueles que se servem das massas, depois de terem-nas engendrado" (Horkheimer \& Adorno, 1956/1973, pp. 85-86) - de outro, os veículos de comunicação mediante "predisposição, estímulo e reação" (p. 87), constituem "perigo social" (p. 87), não apenas por atuarem na base das inclinações psíquicas, mas também por alimentarem o processo sistemático do conformismo. Não só a opinião pública como sucedâneo da razão impossibilita a compreensão do todo, bem como a cultura industrializada turva a consciência do indivíduo ao funcionar como instrumento de determinação dos fins. Como exemplificação, no seu estudo a respeito da televisão - concebida como síntese do cinema e do rádio - Adorno (1953/1969a; $1953 / 1969 b$ ) adverte sobre as mensagens abertas ou encobertas (essas últimas, por serem psicologicamente mais efetivas, são priorizadas) que as produções televisivas transmitem ao expectador; quanto mais completo é o mundo em termos de aparência, tanto menos superável é o surgimento da ideologia. $O$ autor também acrescenta que a televisão (produto do antiespírito objetivo) reproduz a tendência econômica fundante da sociedade contemporânea, que não pretende superar o status quo, ao contrário, reafirma-o; o mundo imaginário, sem lacunas, resulta fragmentário, e mesmo que, inconscientemente, o observador suspeite que a realidade em que vive não coincide com o exibido na tela, resigna-se com a situação, pois a real estranheza que prevalece entre os homens e as coisas é encoberta. As imagens da televisão estão presentes para conferir brilho à vida cinzenta do observador, propiciando, também, um suposto efeito socializador ao reunir membros da família e amigos, cujos laços sociais já se encontram enfraquecidos, pois não há mais espaço para o diálogo.

Os meios de comunicação de massa penetram no dia-a-dia das pessoas e veiculam conteúdos ideológicos. O princípio é a disseminação de programas para que o teleouvinte possa não apenas tolerar o fastio, a náusea e a monotonia do mundo vivido, como, também, aprender a conviver com o próprio sofrimento, ao assistir à desgraça do outro. A televisão não age sozinha, mas em consonância com outros meios de comunicação, cada um com sua lógica específica, apesar de tenderem cada vez mais à uniformização. A aparente objetividade e o formalismo da televisão colaboram com a insensibilidade dos ouvintes, e a frieza e a intransigência para com o outro encobrem as dores da existência. Crochík (2003a) explica isso:

O formalismo, presente na ideologia da racionalidade tecnológica, transforma o desigual em igual, o infeliz em feliz, o oprimido em livre e o injusto em justo, ao negar as condições sociais que geram a infelicidade, a opressão e a injustiça. (p. 18) 
Quanto mais os meios de comunicação se desenvolvem, mais a lógica binária passa a prevalecer, juntamente com a absorção do conteúdo pela forma. A sociabilidade implica adaptação; os clichês e os estereótipos colaboram com a manifestação de atitudes marcadas pela silenciosa aceitação do sofrimento alheio. A responsabilidade de o indivíduo, por exemplo, estar infeliz e/ou oprimido recai nele próprio, e as circunstâncias sociais desumanas não são consideradas.

E mais, a televisão - com seu vocabulário restrito e uniforme - contribui no empobrecimento da percepção acerca da realidade, oferecendo ao telespectador a ilusão de ter encontrado a paz perdida. A televisão colabora com o fortalecimento da realidade existente, na tentativa manifesta de ludibriar e de seduzir o consumidor por meio da redução da tensão entre o veiculado na tela e a vida cotidiana. Já é problemático o fato de a televisão surgir da esfera do entretenimento, e"...quando é proposta para a educação, empresta a essa o caráter de indústria cultural" (Crochík, 2003b, p. 99). A televisão traz a interpretação a priori: substitui a visão de mundo do indivíduo pela tela, de tal forma que, ao obstá-lo de entender a determinação social, a experiência do indivíduo torna-se mecânica e endurecida, conformando-se com a realidade em que vive.

Considerada a ideologia da racionalidade tecnológica, mesmo concebendo o indivíduo como produto do meio sócio-econômico inserido na sociedade que se conserva irracional, apesar de toda racionalização, é possível afirmar que seu corpo e sua psique ${ }^{2}$ vêm sofrendo alterações. Não só sua individualidade vem sendo negada, como vem perdendo a capacidade de resistir diante da engrenagem da cultura de massa. Se a sociedade atual não favorece a satisfação das pulsões dos indivíduos, e contenta-se em converter tudo que encontra a um mero instrumento, o propósito remanescente do ego seria a perpetuação de sua atividade de mediação em um todo irracional? Marcuse (1955/1999b) aponta aspectos importantes na configuração do ego do indivíduo. $O$ indivíduo - com um ego estruturado - tem condições de adequar suas necessidades à realidade externa, bem como de discernir entre o prazer como fim em si mesmo e o prazer sem dano para si próprio e para o meio externo.

A administração, nos dias atuais, volta-se para a aparente racionalidade da vida, não permitindo a autonomia da decisão individual. A preocupação recai não apenas na competência e na solvência de problemas imediatos, como também na conservação da forma atual de operação do capitalismo, de modo que o trabalho passa a ser fim em si mesmo. Se ele traz tal conotação, não podemos considerá-lo como não-dominador, pois envolve a violência, e não a liberdade.

2 No decorrer deste estudo, utilizamos os termos psique e espírito (alma), ainda que não tenham o mesmo significado se formos buscar a gênese desses conceitos. Além do mais, não podemos conceber o corpo e o espírito separados um do outro, entretanto, tal divisão pode ser explicada pela ruptura entre indivíduo, natureza e cultura, que coloca à mostra o exigido pelo caráter formal da ideologia atual. 
É bem sabido que a justiça caminha de mãos dadas com a igualdade e a liberdade, entretanto, não podemos desconsiderar que a violência atinge diversas esferas de nossas vidas, -6r exemplo, família, trabalho e lazer, incapacitando o indivíduo de lutar por seus direitos fundamentais. Como expresso por Adorno (1947/1993):"A mais extrema injustiça transforma-se num simulacro de justiça, a desqualificação dos homens torna-se imagem enganosa de sua igualdade" (p. 170). Apesar da existência das leis, a violência impera, não apenas a física, mas também a psíquica - por meio da repressão do conteúdo das pulsões -, que gera maior hostilidade em relação à cultura. Com isso, a criação de laços vai se tornando difícil de ser realizada, o que compromete a forma como a sociedade vem se constituindo. $\mathrm{O}$ enfraquecimento da ligação entre os membros familiares é um fato e, conseqüentemente, o indivíduo, com o ego debilitado, sente-se solitário e vulnerável sob as condições da burocracia da exploração e da dominação, ficando predisposto ao sofrimento psíquico desde cedo, pois:

A consciência moral e a responsabilidade pessoal degeneram "objetivamente" sob as condições da burocratização total, nas quais é extremamente difícil atribuir-se ainda uma autonomia e onde o funcionamento do aparato determina a autonomia pessoal, pondo-se acima dela. Essa representação corrente contém, entretanto, um forte elemento ideológico: o conceito de "burocracia" recobre (como o de "administração") realidades muito diferentes e até mesmo antagônicas: a burocracia da dominação e da exploração é algo muito diferente da "administração das coisas", que visa ao desenvolvimento e à satisfação planejados das necessidades individuais vitais (Marcuse, 1963/1998, p. 98).

Esse trecho suscita-nos algumas reflexões: 1 . A falta de autonomia do indivíduo relaciona-se com as condições de burocratização da totalidade social; 2 . As determinações sociais interferem nas determinações psíquicas do indivíduo. Este, ao perder a capacidade de fazer uma análise da sociedade, propicia que as normas sociais se conservem sob o domínio do aparato. A responsabilidade pessoal e a consciência moral desvinculam-se das condições sociais, gerando o sofrimento do corpo e da psique; 3 . O conceito de burocracia (da exploração e da dominação), sob um acentuado teor ideológico, alia-se ao conceito de administração, de modo que a tensão entre ambos é enfraquecida. $O$ indivíduo deixa de refletir sobre seus próprios objetivos para ajustar-se ao todo social; 4 . Com a degeneração da responsabilidade pessoal e da consciência moral, a máxima passa a ser a reprodução da irracionalidade nas diversas instâncias da vida do indivíduo.

No que se refere, mais uma vez, ao âmbito familiar, o enfraquecimento da autoridade da família resulta no enfraquecimento do superego, solapando não apenas a capacidade de julgar do indivíduo, como também minando a condição de ser responsável por seus atos. Quanto mais narcisista, mais o indivíduo fica vulnerável ao poder e ao domínio social. 
Esclarecemos que o ponto de partida para a elaboração da pesquisa foi a tese de livre-docência de Crochík (1999), em que desenvolve uma pesquisa empírica com o objetivo de verificar se há correlação significativa entre a ideologia da racionalidade tecnológica e as características narcisistas de personalidade. $O$ autor chama a atenção para o fato de que a sociedade media a relação entre ideologia e personalidade e que essa relação é histórica. Na parte de sua tese em que trata da discussão entre o narcisismo e a autoconservação, há o seguinte:

O narcisista quer nas suas relações com o mundo, no tocante à autoconservação, quer com os objetos de amor, quer na constituição de seu ideal, teria a tendência permanente e insistente para a regressão a aquele estado de não diferenciação, enquanto aquele que não o é pode ao longo de seu desenvolvimento presenciar a supremacia do mundo externo sobre si mesmo e, encontrando nesse motivos para prazer e possibilidades de combate ao sofrimento, pode resistir mais aos apelos narcisistas. (Crochík, 1999, pp. 95-96)

Percebemos que o autor aproxima o narcisismo da propensão do indivíduo à regressão. Essa se relaciona com a indiferenciação constantemente solicitada pela cultura atual - que demanda ordenações psíquicas para que o indivíduo não se diferencie da realidade social -, sendo que essa possibilitaria oportunidades para sua individuação. A tese desse paradoxo leva ao sofrimento humano, pois os indivíduos submetem-se às exigências ideológicas.

Crochík (1999) também aproxima os conceitos de narcisismo e de melancolia, a partir do texto freudiano Psicologia de grupos e análise do ego, asseverando:

se a melancolia provém de uma relação amorosa, o tipo de vínculo que a motivou pode estar ligado ao narcisismo, o que ocasionaria a pouca resistência da catexia libidinal e a força de atração que a faz se voltar para o ego, que pela identificação converte-se no objeto. (p. 103)

A escolha objetal não deixa de ser realizada mediante uma base narcisista. Ao se deparar com dificuldades, a catexia objetal pode retroceder ao narcisismo.

O que parece estar em evidência, na pesquisa de Crochík (1999), é o enfraquecimento do ego, levando-nos a reconhecer que a tendência à regressão está presente não só no narcisismo, mas, também, na melancolia, tendo em vista a necessidade de autoconservação. Por assim dizer, convém distinguirmos o enfraquecimento do ego em face das condições objetivas: "Contrapondo-se ao seu caráter pervertido que busca o prazer no próprio corpo, tomado como objeto de amor, o narcisismo se apresenta como algo universal necessário para a sobrevivência" (p. 89). Como afirma o autor, em um outro texto: 
nem a sociedade irracional criticada por Adorno, nem o indivíduo que abdica da consciência, ao abandonar as relações com os objetos, isto é, o tipo narcisista, podem ser reduzidos à nosografia psicanalítica; antes, deve-se buscar, nas exigências sociais, as reações individuais a elas. (Crochík, 2000a, p. 22)

Observa-se que o estudo do narcisismo por intermédio do indivíduo enquanto mônada é insuficiente, o que demanda uma reflexão sobre a relação indivíduo, cultura e sociedade. Nesse sentido, Adorno (1951/1998b) chama a atenção para uma dimensão importante:"Somente o conformismo poderia aceitar a atual insanidade objetiva como um simples acidente de percurso do desenvolvimento histórico. A regressão é essencial ao desenvolvimento conseqüente da dominação" (p. 109). Com certeza, na época atual,"a sociedade se autonomiza cada vez mais em relação aos seus membros e o indivíduo vive uma regressão psíquica maior" (Crochík, 2000b, p. 530) e, via de regra, o ego sofre com essa regressão. A defesa pessoal, além de manifestar-se na domesticação do corpo e da psique, materializa-se na negação do desejo humano. No entendimento de Adorno (1969/1995a):

o indivíduo não está menos cativo dentro de si que dentro da universalidade, da sociedade. Daí o interesse em reinterpretar sua prisão como liberdade.O cativeiro categorial da consciência individual reproduz o cativeiro real de cada indivíduo. Mesmo o olhar da consciência que descobre aquele cativeiro é determinado pelas formas que ele Ihe implantou. No cativeiro em si, poderiam os homens perceber o cativeiro social: impedir tal coisa constituiu e constitui um interesse, capital da conservação do "status quo". (pp. 191-192, destaque do autor)

O cativeiro individual tem uma verdade diversa do cativeiro social, mas mesmo essa veracidade deve ser remetida ao que a sociedade requer do indivíduo para o seu ajustamento. $\mathrm{O}$ autor argumenta que em cada época a sociedade produz a personalidade - tipo de distribuição da energia psíquica - que necessita:

Um mundo em que a técnica ocupa uma posição tão decisiva como acontece atualmente, gera pessoas tecnológicas, afinadas com a técnica. Isto tem a sua racionalidade boa: em seu plano mais restrito elas serão menos influenciáveis, com as correspondentes conseqüências no plano geral. Por outro lado, na relação atual com a técnica existe algo de exagerado, irracional, patogênico.Isto se vincula ao "véu tecnológico." Os homens inclinam-se a considerar a técnica como sendo algo em si mesma, um fim em si mesmo, uma força própria, esquecendo que ela é a extensão do braço dos homens. Os meios - e a técnica é um conceito de meios dirigidos à autoconservação da espécie humana - são fetichizados, por que os fins - uma vida humana digna - encontram-se encobertos e desconectados da consciência das pessoas. (Adorno, 1967/2000a, pp. 132-133, destaque do autor)

Ao que parece, a técnica apoderou-se do corpo e do espírito das pessoas devido às condições materiais que estão sendo estabelecidas por 
uma história de dominação e coerção. O caráter formal de dominação da ideologia da racionalidade tecnológica, mediante a adesão dos indivíduos aos fenômenos de massa, propicia o sofrimento do corpo e da psique humana. Para Adorno (1969/2000b, p. 181), a emancipação é difícil de ser concretizada devido à forma como o mundo está organizado. O princípio da heteronomia, além de propiciar o enfraquecimento do eu, impossibilita que os indivíduos sigam suas próprias determinações. A fragilidade do eu e a regressão psíquica estão presentes no indivíduo narcisista e no indivíduo melancólico, e a "A expressão da fraqueza e da impotência da alma individual é testemunho da violência contra a humanidade naquelas pessoas que, como vítimas, representam o todo" (Adorno, 1953/1998c, p. 172). A coação contra a humanidade deu-nos a chave para a compreensão do estado de irracionalismo geral. O desalento e a inibição do indivíduo indicam ser a força motriz da dor de existir do melancólico que se sente, provavelmente, impotente diante da violência do todo.

Freud (1926/1976b) coloca a depressão ${ }^{3}$ no campo das inibições:

Quando o ego se vê envolvido em uma tarefa psíquica particularmente difícil, como ocorre no luto, ou quando se verifica uma... supressão de afeto, ou quando um fluxo contínuo de fantasias sexuais tem de ser mantido sob controle, ele perde uma quantidade tão grande de energia à sua disposição que tem de reduzir o dispêndio da mesma em muitos pontos ao mesmo tempo... Temos aqui um ponto a partir do qual deve ser possível chegar a uma compreensão da condição da inibição geral que caracteriza estados de depressão, inclusive a mais grave de suas formas, a melancolia. (pp. 110-111)

A melancolia decorre de restrições das funções do ego, resultante de uma perda significativa de energia, de perda de um objeto, caracterizandose pelo desejo inibido, pela inibição generalizada.

Como bem destaca Crochík (1999), a teoria freudiana estabelece uma correspondência entre narcisismo, como sofrimento psíquico, e melancolia, cuja representação exprime-se pela modificação do ego em função de um objeto perdido, ainda que não se conheça que objeto é esse.

$\mathrm{Na}$ alteração do ego estão presentes sentimentos de inferioridade e de auto-recriminação, incapacidade de amar; falta de interesse pela realidade externa, dentre outros. Não é fortuito que Freud (1917/1976c) afirma que:

A tendência do melancólico para o suicídio torna-se mais compreensível se considerarmos que o ressentimento do paciente atinge de um só golpe seu próprio ego e o objeto amado e odiado. Na melancolia, bem como em outros distúrbios narcísicos, emerge, um acento especial, um traço particular na vida

3 Ao recorrermos a Freud, constatamos que o autor emprega, no transcurso de sua obra, os termos melancolia, distúrbio narcísico, psiconeurose narcísica, neurose narcísica, depressão e depressão melancólica, sem distingui-los claramente. 
emocional do paciente... acostumamos a descrever como "ambivalência". Com isso queremos significar que estão sendo dirigidos à mesma pessoa sentimentos contrários - amorosos e hostis. (p.498, destaque do autor)

Com relação ao sentimento de ambivalência, traço fundamental dos investimentos vividos pelo melancólico em relação ao objeto, Freud (1917/1974a) argumenta que, na melancolia, a relação com o objeto é complicada devido a esse sentimento. Esse pode ser constitucional - um elemento de toda relação amorosa constituída por esse ego singular - ou decorrer exatamente daquelas experiências que implicaram a ameaça da perda do objeto. Aqui, podemos expor o que pensa Freud (1917/1974a), que por meio da analogia entre melancolia e luto nos adverte sobre a manifestação da inibição melancólica:

No luto, verificamos que a inibição e a perda de interesse são plenamente explicadas pelo trabalho do luto no qual o ego é absorvido. Na melancolia, a perda desconhecida resultará num trabalho interno semelhante, e será, portanto, responsável pela inibição melancólica. A diferença consiste em que a inibição do melancólico nos parece enigmática porque não podemos ver o que é que o está absorvendo tão completamente. O melancólico exibe ainda uma outra coisa que está ausente no luto - uma diminuição extraordinária de sua auto-estima, um empobrecimento de seu ego em grande escala. (p. 278)

Para Freud (1917/1974a), a melancolia é algo semelhante ao luto, em que existe desalento, falta de amor, retração dos investimentos nos objetos, em decorrência de uma perda não sabida, não subjetivada. O melancólico não entende, conscientemente, o que ele acredita ter perdido, diferentemente do que ocorre no luto. $O$ sujeito, no luto, sabe o que perdeu; o melancólico não sabe. Na melancolia, o que se perdeu, inconscientemente, foi o próprio ego que deu lugar ao objeto com o qual rompeu a catexia. Freud (1917/1974a) acrescenta que:

O complexo de melancolia se comporta como uma ferida aberta, atraindo a si as energias catexiais - que nas neuroses de transferência denominamos de "anticatexias" - provenientes de todas as direções, e esvaziando o ego até este ficar totalmente empobrecido (pp. 285-286, destaque do autor).

Um pouco mais adiante, na mesma página, indaga "...se uma perda no ego, independentemente do objeto - um golpe puramente narcisista contra o ego - não bastará para produzir o quadro de melancolia". Como afirma, em um outro texto:

A tese de que as neuroses e as psicoses se originam nos conflitos do ego com as suas diversas instâncias governantes - isto é, portanto, de que elas refletem um fracasso no funcionamento do ego, que se vê em dificuldades para reconciliar 
todas as várias exigências feitas a ele - essa tese precisa ser suplementada em mais um ponto. Seria desejável saber em que circunstâncias e por que meios o ego pode ter êxito em emergir de tais conflitos, que certamente estão sempre presentes, sem cair enfermo. (Freud, 1924/1976d, p. 193)

Nesse ponto em que Freud dá destaque ao fortalecimento do ego, cabe-nos apontar o que pensa Adorno. Para esse autor, Freud reconhece tacitamente que a teoria das pulsões por si só não fundamenta os comportamentos sociais; na diferenciação entre pulsão de ego e pulsão de objeto está codificada a diferença. A psicanálise, sem dúvida, tem-se ocupado, sobretudo, das pulsões do objeto, descuidando-se da pulsão do ego; o organismo é que se retrai, pois o ego do indivíduo, levado à regressão pela sociedade, torna-se frágil (Adorno, 1955/1986). Além do mais, na concepção de Adorno (1955/1986), a atitude naturalista de Freud é resultante da exclusão do princípio do novo, na redução da vida psíquica à repetição do que ocorreu. Assim, em contradição com a doutrina freudiana da atemporalidade do inconsciente, para Adorno, certamente, estão presentes, nessa instância, componentes históricos concretos da experiência infantil mais tenra. Ele argumenta, também, que o conceito de ego é dialético, psíquico e não psíquico, fragmento de libido e representante do mundo, mas que Freud não tratou dessa dialética.

Dado o sacrifício constante, o enfraquecimento, a destruição do ego é que está em evidência no melancólico:"Fechamento em si mesmo, narcisação primária, tendência a tomar o Ego por objeto e as queixas infinitas que disso são corolários, a ponto de conseguir destruir o único objeto que ele pode alcançar: o Ego" (Hassoun, 1995/2002, p. 78). A destruição do ego leva-nos ao que pensa Adorno (1947/1993):

Quanto mais alguém toma para si o partido de sua agressão, tanto mais perfeitamente representa o princípio repressivo da sociedade. Neste sentido, mais talvez do que em qualquer outro, é válida a afirmação de que o mais individual é o mais universal. (p. 38)

É na busca de interesses notadamente particulares dos indivíduos que se pode analisar com maior precisão possível a substância do coletivo na universalidade social repressiva. Como afirma Marcuse (1955/1999b):

Segundo Freud, a história do homem é a história da sua repressão. A cultura coage tanto a sua existência social como a biológica, não só partes do ser humano, mas também sua própria estrutura instintiva. Contudo, essa coação é a própria precondição do progresso. (p.33)

Tratando-se do progresso, esse não apenas domina o particular, por meio da adaptação do indivíduo na sociedade capitalista, como, também, fortalece a ordem atual, e o indivíduo não consegue se opor à totalidade 
devido à miséria do corpo e do espírito. A organização social reproduz a dominação. Os indivíduos, calcados em uma razão afastada dos interesses humanos, ficam inclinados a agir de forma imediata e irracional. Se, por um lado, o indivíduo sente dificuldade de distinguir o que é o mundo externo e o que é o mundo interno, de modo que tal indistinção já é defesa contra o sofrimento, por outro lado, a ruptura entre razão e vida pode resultar no fato de o indivíduo não mais entender o que se vive por falta de viver o que se entende. Ou, ainda, para Adorno (1968/2004), o indivíduo com consciência crítica, quanto mais compreende a sociedade, tanto menos com ela se conforma e tanto mais penoso para ele é tornar-se útil no seu seio. $\mathrm{O}$ sofrimento existe de fato e a necessidade de autoconservação excede a capacidade de o indivíduo resistir ante os regulamentos sociais para a manutenção da ordem irracional.

Não apenas os conceitos de dominação e de ideologia da racionalidade tecnológica estão intimamente relacionados, como, também, os conceitos de narcisismo, de melancolia e de ideologia da racionalidade tecnológica. A melancolia é uma forma de o narcisismo manifestar-se; toda melancolia tem marcas do narcisismo. Por seu lado, o narcisismo apresenta-se na melancolia, mas não somente nela, a exemplo do tipo manipulador.

Em se tratando de configurações psíquicas que a sociedade demanda para a reprodução do standard estabelecido, podemos extrair considerações fecundas a partir do que afirma Crochík (2004): 1. O indivíduo está cada vez mais se identificando com o todo social irracional, de tal modo que a regressão individual é notória; 2 . As conformações narcisistas - incluindo o tipo manipulador - melancólicas, sadomasoquistas e compulsivas guardam certa relação, e estão associadas com a defesa irracional da técnica; 3 . A síndrome de pânico, na atual sociedade, é decorrente de ameaças constantes; 4 . A sociedade, que sacrifica seu meio cultural mediante a dominação técnica, não tem sensibilidade pelas necessidades humanas e, conseqüentemente, a cultura que propicia o narcisismo torna a totalidade sombria e melancólica.

Nos dias atuais, é complicado o indivíduo reconhecer-se no outro e perceber a presença da objetividade em si mesmo; e, apesar de o indivíduo sentir dificuldade de promover uma análise crítica da realidade, adaptando-se a um ideal coletivo que o desconsidera a todo o momento, não pretendemos fazer uma apologia do sofrimento. Não apenas o sofrimento remete às forças ideológicas que escravizam os indivíduos como, também, as pessoas encontram possibilidade de reversibilidade da dor mediante $o$ contato com a realidade externa. O ponto central indica ser o fortalecimento da razão diante da sociedade atual em que o ego (consciência) perdeu o seu caráter de instância mediadora - do conceito, do juízo, da razão, da memória, do pensamento, da atenção, da emoção, da vontade, do desejo, da idéia e da linguagem. E, sem dúvida, como afirma Tiburi (1995): "A razão só pode ser racional quando prova a si mesma sua racionalidade e percebe 
que esta não anda só, como têm demonstrado a realidade e a história" (p. 64). Na prontidão para a autoconservação, não apenas o corpo é negado como, também, o espírito, sendo ambos regidos pela automação e consumação, como assevera Adorno (1967/2000a):

É possível falar da claustrofobia das pessoas no mundo administrado, um sentimento de encontrar-se enclausurado numa situação cada vez mais socializada, como uma rede densamente interconectada. Quanto mais densa é a rede, mais se procura escapar, ao mesmo tempo em que precisamente a sua densidade impede a saída. Isto aumenta a raiva contra a civilização. Esta torna-se alvo de uma rebelião violenta e irracional. (p. 122)

Na sociedade atual, a claustrofobia, decerto, está presente tanto no narcisista quanto no melancólico, havendo uma correlação entre a ideologia da racionalidade tecnológica, o tédio e a claustrofobia. Da mesma forma, a noção de "hibernação social", conforme expressão de Costa (1989, p. 134), aproxima-se da "claustrofobia da humanidade", que se traduz, de acordo com Crochík (2001, p. 4), em um excesso de regras da sociedade versus indignação contra elas; a crueldade - formação reativa do desejo de proximidade dos corpos - é um dos sinais dessa claustrofobia, e, não por acaso, a passividade ativa entremostra o sofrimento de desamparo interior. O indivíduo fica inclinado aos valores, às crenças e às idéias disseminadas pela indústria cultural, que passam a intervir no modo de agir e de pensar individual, interferindo na possibilidade de transformação da realidade histórica mantida socialmente pela miséria do corpo e do espírito:"Quanto menos promessas a indústria cultural tem a fazer, quanto menos ela consegue dar uma explicação da vida como algo dotado de sentido, mais vazia torna-se necessariamente a ideologia que ela difunde" (Horkheimer \& Adorno, 1947/1985, p. 137). E mais:

A ideologia... reduzida a um discurso vago e descompromissado nem por isso se torna mais transparente e, tampouco, mais fraca. Justamente sua vagueza, a aversão quase científica a fixar-se em qualquer coisa que não se deixe verificar, funciona como instrumento da dominação. (p. 138)

Os fenômenos de massa fazem parte de nosso cotidiano sem que possamos refletir sobre sua irracionalidade, dada a manipulação constante mediante o planejado pela indústria cultural. O indivíduo tende a submeter-se aos princípios de troca para a reprodução do establishment.

É bom enfatizar que o narcisismo e a melancolia são fenômenos decorrentes de condições subjetivas e objetivas. A melancolia é uma afecção do ego, na esfera mesmo em que nele se inscreve a pulsão de morte, indagando Freud (1923/1976e): como pode na melancolia, o superego tornar-se uma espécie de espaço privilegiado para os instintos de morte? A moralidade, decorrente de necessidades psíquicas e sociais, guarda relação 
com a melancolia e, mais uma vez, a crueldade se faz presente. $O$ superego supermoral castiga o ego do indivíduo, e quanto mais o indivíduo controla sua agressividade, mais se torna intensa a tendência de seu ideal à agressividade contra seu ego.

O mundo moderno consiste na retirada do sujeito para sua interioridade, na regressão a uma vida despida de significado, e, quando se priva de toda claridade exterior, é no interior do indivíduo melancólico que precisamos detectar as tendências a cair na dominação. No entanto, ao se deleitar com o recolhimento defensivo, a origem da solidão torna-se manifesta, considerando-se que:

Com a sociedade, reproduz-se de maneira amplificada a solidão. Esse mecanismo prevalece até mesmo nas mais ternas manifestações do sentimento, a tal ponto que o próprio amor, a fim de abrir um caminho qualquer até o outro, é forçado a tamanha frieza que se destrói com a própria realização. (Horkheimer \& Adorno, 1947/1985, p. 75)

Com isso, não podemos desvincular a consciência individual das demandas objetivas do aparato social. Sob tais circunstâncias, o que parece estar em jogo é a "dessublimação institucionalizada":

parece, assim, ser um aspecto da "conquista da transcendência" conseguida pela sociedade unidimensional. Assim como essa sociedade tende a reduzir e até a absorver a oposição... no âmbito da política e da cultura superior, também tende a fazê-lo na esfera instintiva. O resultado é a atrofia dos órgãos mentais, impedindo-os de perceber as contradições e alternativas e, na única dimensão restante da racionalidade tecnológica, prevalece a Consciência Feliz. Ela reflete a crença em que o real seja racional e em que o sistema estabelecido a despeito de tudo entrega as mercadorias. As pessoas são levadas a ver no aparato produtivo o agente eficaz de pensamento e ação ao qual se devem render seu pensamento e ação pessoais. E, nessa transferência, o aparato também assume o papel de agente moral. A consciência é absorvida por espoliação, pela necessidade geral de coisas (Marcuse, 1964/1967, p. 88, itálicos do autor)

A falsa consciência tem por base a repressão instintiva e, conseqüentemente, o sofrimento do corpo e da psique. No momento em que o princípio individual é separado do princípio social, deslocando-se para o aparato produtivo, resta ao indivíduo tomar consciência de sua própria desrazão. Mais ainda:

a perda da consciência em razão das liberdades satisfatórias concedidas por uma sociedade sem liberdade favorece uma consciência feliz que facilita a aceitação dos malefícios dessa sociedade. É o indício de autonomia e compreensão em declínio. (Marcuse, 1964/1967, p. 85, itálicos do autor) 
A consciência feliz resulta da materialização da racionalidade tecnológica nos indivíduos. Esses (integrantes de uma sociedade não-livre) adaptam-se aos aspectos regressivos da sociedade e tendem a reproduzir a ficção de uma totalidade digna. A sociedade unidimensional atinge seu intento, a satisfação mediata é substituída pela imediata. A consciência feliz reflete a crença de que o real seja racional, e o indivíduo - narcisista e melancólico - diante da dissolução da cultura bidimensional, é completamente impedido de perceber as contradições da ordem estabelecida, de modo que seu pensamento, sua ação pessoal e sua moralidade, ao trazerem a marca da ideologia da racionalidade tecnológica, passam a resultar da incorporação e da reprodução da realidade vivida, preservando, assim, a dominação social. Aliado a isso, como vem ocorrendo a autonomização da sociedade em relação ao indivíduo, esse projeta o sofrimento sobre o que Ihe é acarretado pela sociedade, contra a razão em si, e a consciência feliz é o estado que mascara a ambigüidade presente na melancolia. Por seu lado, o conflito entre resistência e adaptação em face da repressão nas diferentes esferas da vida impede a mobilidade da consciência, ocorrendo uma convivência narcisista e melancólica com a realidade estabelecida.

O confinamento do sujeito em si mesmo é o protótipo de que o tédio “...é o reflexo do cinza objetivo" (Adorno, 1969/1995b, p. 76), ou melhor, o"tédio é o desespero objetivo. Mas, ao mesmo tempo, também a expressão de deformações que a constituição global da sociedade produz nas pessoas" (p. 76). O fortalecimento do ego propicia ao indivíduo passar da falsa consciência para a verdadeira. No mesmo sentido, a possibilidade de uma objeção ao todo pode favorecer a transformação de seu estilo de vida individual por meio do abandono da satisfação repressiva - negação dos fins imediatos e dos interesses adquiridos -, pois, decerto, a reprodução do existente impede a individuação. Na sociedade atual, o estado de sujeição excede ao de liberdade, levando-nos a pressupor que a interioridade e a subjetividade passam a ser, simplesmente, tonalidades no interior da uniformização da oferta:

O tédio existe em função da vida sob a coação do trabalho e sob a rigorosa divisão do trabalho. Não teria que existir. Sempre que a conduta no tempo livre é verdadeiramente autônoma, determinada pelas próprias pessoas enquanto seres livres, é difícil que se instale o tédio; tampouco ali onde elas perseguem seu anseio de felicidade, ou onde sua atividade no tempo livre é racional em si mesma, como algo em si pleno de sentido... Se as pessoas pudessem decidir sobre si mesmas e sobre suas vidas, se não estivessem encerradas no sempreigual, então não se entediariam. (Adorno, 1969/1995b, p. 76)

A manutenção do sempre-igual paralisa as forças de oposição. A irracionalidade do sistema exprime-se na rígida divisão e coerção do trabalho. É complicada a convivência humana nos dias atuais e, não por acaso, o traço característico desse momento é a atrofia da capacidade de o indivíduo 
decidir por si próprio. Com isso, quanto menos alguém toma para si a organização de sua vida, tanto mais fica susceptível ao tédio.

Dessa maneira, é possível aproximar o tédio não apenas da ideologia da racionalidade tecnológica como também do narcisismo e da melancolia. Adorno (1959/1996), em um outro texto, chama-nos ainda a atenção para outro aspecto importante: "A desumanização implantada pelo processo capitalista de produção negou aos trabalhadores todos os pressupostos para a formação e, acima de tudo, o ócio" (p. 393). A integração do tempo livre é obtida sem maiores impedimentos; as pessoas não entendem o quanto não são livres onde mais livres se percebem, porque o preceito dessa falta de liberdade foi abstraído delas (Adorno, 1969/1995b). Como argumenta, em um outro texto:

A atomização não está em progresso apenas entre os seres humanos, mas também no interior de cada indivíduo, entre as esferas de sua vida. Nenhuma realização pode estar ligada ao trabalho, que perderia assim sua modéstia funcional na totalidade dos fins; nenhuma centelha da reflexão pode invadir as horas de lazer, pois ela poderia saltar daí para a esfera do trabalho e incendiá-la. Enquanto em sua estrutura trabalho e divertimento se tornam cada vez mais semelhantes, as pessoas passam a separá-los de um modo cada vez mais rígido com invisíveis linhas de demarcação. De ambos foram expulsos, na mesma proporção, o prazer e o espírito. Lá como cá imperam a seriedade sem humor e a pseudo-atividade. (Adorno, 1947/1993, p. 114)

De passagem, a pseudo-atividade é um meio que o indivíduo recorre para encobrir sua fragilidade diante da debilidade objetiva de todos na sociedade atual. Se, de um lado, a pseudo-atividade - práxis não receptiva à teoria e ao conhecimento, e que perde o contato com o objeto - é resultante das condições objetivas (Adorno, 1969/1995c), de outro, a pseudo-atividade é a tendência para a auto-renúncia, único espaço pelo qual ainda se pressupõe assegurar a autoconservação. A segurança refere-se ao assentimento à mais intensa insegurança, concebida como prerrogativa para a fuga que leve a um outro lugar (Adorno, 1947/1993). É certo que a "seriedade sem humor" e a "pseudo-atividade" entremostram a desumanização da totalidade e, como afirma Adorno (1969/1995c, p. 207),"A maioria dos ativistas carece de humor." Desse modo, podemos correlacionar a seriedade sem humor - desprovida de espírito e de prazer - com a ideologia da racionalidade tecnológica e com a melancolia. A dominação social está presente nas diversas esferas da vida do indivíduo, incluindo o trabalho e o lazer que se tornam cada vez mais entrelaçados, apesar do esforço do indivíduo em separá-los. E, para Marcuse (1955/1999b):

O que se procura é a solução de um problema "político": a libertação do homem das condições existenciais inumanas... O impulso lúdico é o veículo dessa libertação. O impulso não tem por alvo jogar "com" alguma coisa; antes, é o jogo 
da própria vida - para além de carências e compulsões externas - a manifestação de uma existência sem medo nem ansiedade e, assim, a manifestação da própria liberdade. O homem só é livre quando está livre de coações, externas e internas, físicas e morais - quando não é reprimido pela lei nem pela necessidade. Mas tal coação é a realidade. Assim, num sentido estrito, liberdade é a emancipação de uma realidade estabelecida: o homem está livre quando a "realidade perde a sua seriedade" e quando a sua necessidade "se ilumina" ... Numa civilização autenticamente humana, a existência humana jogará em vez de labutar com esforço, e o homem viverá exibindo-se, em vez de permanecer vergado à necessidade. (p. 167, destaques do autor)

À medida que o indivíduo ajusta-se à realidade estabelecida de forma desmedida, ele nega tudo que subsiste como impulso lúdico em sua existência.É nesse aspecto que se baseia a expressão condições desumanas. Em virtude da falta de liberdade, a exibição traduz-se na "livre manifestação de potencialidades" (Marcuse, 1955/1999b, p. 169), e a seriedade com humor está intimamente relacionada com a realidade que "perde a sua seriedade", no momento em que não apenas as ameaças externas e internas encontram guarida na livre criação humana, como também as necessidades e as carências podem ser satisfeitas sem trabalho alienado.

É bom lembrar que, para Freud (1927/1974b):

o humor tem algo de liberador a seu respeito, mas possui também qualquer coisa de grandeza e elevação... Essa grandeza reside claramente no triunfo do narcisismo, na afirmação vitoriosa da invulnerabilidade do ego. $O$ ego se recusa a ser afligido pelas provocações da realidade, a permitir que seja compelido a sofrer. Insiste em que não pode ser afetado pelos traumas do mundo externo; demonstra, na verdade, que esses traumas para ele não passam de ocasiões para obter prazer. Esse último aspecto constitui um elemento inteiramente essencial do humor. (p. 190)

É precisamente o reconhecimento de que o narcisismo, ao aliar-se ao humor, pode ser um antídoto contra a vulnerabilidade do ego. Para Adorno (1955/1986), todos os mecanismos de defesa têm uma marca de narcisismo, e todos os tipos de personalidade têm algo de narcisista. Pressupomos, então, tomando as palavras de Freud (1914/1974c), que, nesse caso, o narcisismo não seria considerado uma perversão, "...mas o complemento libidinal do egoísmo do instinto de autopreservação, que, em certa medida, pode justificavelmente ser atribuído a toda criatura viva" (p.90).

Analogamente ao humor:

Se o riso é até hoje o sinal da violência, o prorrompimento de uma natureza cega e insensível, ele não deixa de conter o elemento contrário: com o riso, a natureza cega toma consciência de si mesma enquanto tal e se priva assim da violência destruidora.(Horkheimer \& Adorno, 1947/1985, p. 78) 
A exigência da eliminação da violência já está engendrada no plano das necessidades, de modo que tanto o riso quanto o humor derivam do fato de que não existe mais a liberdade do indivíduo. Não obstante, os autores sinalizam para além da servidão e para além do endurecimento interior. É preciso reconhecer o narcisismo, a melancolia e a ideologia da racionalidade tecnológica como fenômenos sócio-históricos. A compreensão do todo, mediante o estudo desses conceitos, pode servir para entendermos o que leva o indivíduo à manutenção e ao fortalecimento da sociedade existente e visualizarmos os meios que ele dispõe para resistir à dominação social em que a perturbação do corpo e do espírito implica a natureza negada. Não sem razão, a marca do sofrimento vivido é um fato diante da identificação do indivíduo narcisista e do indivíduo melancólico ao todo sombrio, dando margem a comportamentos imobilistas e adaptativos em uma totalidade social em que a racionalidade tecnológica invade as áreas públicas e privadas "...com a indicação de que se alcance o melhor e se evite o pior" (Horkheimer, 1946/2000, p.51), conciliando-se, no entanto, com o mal-estar na cultura atual.

\title{
Body and psychic suffering under social domination
}

\begin{abstract}
This text is the result of theoretical research on The Ideology of technological rationality, narcissism and melancholy, marks of suffering, which had for its objective the verification of the relation between narcissism, melancholy and the ideology of technological rationality through the mediation of some concepts, such as the culture industry, mass phenomena that tend to reproduce social domination in diverse environments of the life of the individual in current society. To this end, we used the concepts of authors and researchers of the Critical Theory of Society and Freudian Theory.
\end{abstract}

Keywords: Critical theory of society. Social domination. Ideology of technological rationality.

\section{La souffrance du corps et de la psyché par la contrainte sociale}

Résumé: Ce texte résulte d'une recherche théorique nommée L'idéologie de la rationalité thécnologique, le narcissisme et la mélancolie : marques de la souffrance, qui a comme but vérifier le rapport entre le narcissisme, la mélancolie et l'idéologie de la rationalité thécnologique au moyen de quelques concepts médiateurs, tels que l'industrie culturelle, les phénomènes de masse, qui tendent à reproduire la 
contrainte sociale dans des divers domaines de la vie de l'individu dans la société actuelle.Pour élaborer ce sujet, nous avons utilisé les écrits d'auteurs et des studieux de la Théorie Critique de la Société et de la Théorie Freudienne.

Mots-clés: Théorie critique de la société. Contrainte sociale.Idéologie de la rationalité thécnologique.

\section{El sufrimiento del cuerpo y de la psique bajo la denominación social}

Resumen: El texto es el resultado de la investigación teórica nombrada La ideología de la racionalidad tecnológica, el narcisismo y la melancolía: huellas del sufrimiento. Tiene el objetivo de comprobar la relación entre el narcisismo, la melancolía y la ideología de la racionalidad tecnológica por intermedio de algunos conceptos mediadores. Éstos son la industria cultural y fenómenos masivos que procuran reproducir la dominación social en las diversas esferas de la vida del sujeto en la actual sociedad. Para la realización, utilizamos escritos de autores y expertos en Teoría Crítica de la Sociedad y Teoría del Freudismo.

Palabras-claves: Teoría Crítica de la Sociedad; dominación social; ideología de la racionalidad tecnológica.

\section{Referências}

Adorno, T. W. (1969a). Prologo a la televisión. In Intervenciones: nueve modelos de critica (pp. 63-74). Venezuela: Monte Avila. (Trabalho original publicado em 1953)

Adorno, T. W. (1969b). La television como ideología. In Intervenciones: nueve modelos de critica (pp. 75-89). Venezuela: Monte Avila. (Trabalho original publicado em 1953)

Adorno, T. W. (1986). Acerca de la relación entre sociología y psicología. In H. Jensen, Teoria crítica del sujeto (pp. 36-83). Buenos Aires: Siglo XXI. (Trabalho original publicado em 1955)

Adorno, T. W. (1993). Minima moralia: reflexões a partir da vida danificada (L. E. Bicca, trad., 2a ed.). São Paulo: Ática. (Trabalho original publicado em 1947)

Adorno, T. W. (1995a). Sobre sujeito e objeto. In T. W. Adorno, Palavras e sinais: modelos críticos 2 (M. H. Ruschel, trad., pp. 181-201). Rio de Janeiro: Vozes. (Trabalho original publicado em 1969)

Adorno, T. W. (1995b). Tempo livre. In T. W. Adorno, Palavras e sinais: modelos críticos 2 (M. H. Ruschel, trad., pp. 70-82). Rio de Janeiro: Vozes. (Trabalho original publicado em 1969) 
Adorno, T. W. (1995c). Notas marginais sobre teoria e práxis. In T. W. Adorno, Palavras e sinais: modelos críticos 2 (M. H. Ruschel, trad., pp. 202-229). Rio de Janeiro: Vozes. (Trabalho original publicado em 1969)

Adorno, T. W. (1996). Teoria da semicultura. Educação e sociedade. Revista de Ciência da Educação (56), 388-411. (Trabalho original publicado em 1959)

Adorno, T. W. (1998a). Crítica cultural e sociedade. In T. W. Adorno, Prismas: crítica cultural e sociedade (A. Wernet \& J. M. B. de Almeida, trads., pp. 7-26). São Paulo: Ática. (Trabalho original publicado em 1951)

Adorno, T. W. (1998b). Aldous Huxley e a utopia. In T. W. Adorno, Prismas: crítica cultural e sociedade (A. Wernet \& J. M. B. de Almeida, trads., pp. 91-115). São Paulo: Ática. (Trabalho original publicado em 1951)

Adorno, T. W. (1998c). Arnold Shoenberg (1874-1951). In T. W. Adorno, Prismas: crítica cultural e sociedade (A. Wernet \& J. M. B. de Almeida, trads., pp. 145-172). São Paulo: Ática. (Trabalho original publicado em 1953)

Adorno, T. W. (2000a). Educação após Auschwitz. In T. W. Adorno (2000), Educação e emancipação (W. L. Maar, trad., 2a ed., pp. 119-138). Rio de Janeiro: Paz e Terra. (Trabalho original publicado em 1967)

Adorno, T. W. (2000b). Educação e emancipação. In T. W. Adorno, Educação e emancipação (W. L. Maar, trad., 2a ed., pp. 169-185). Rio de Janeiro: Paz e Terra. (Trabalho original publicado em 1969)

Adorno, T. W. (2004). Lições de sociologia (J. T. Proença - Lições 1 a 3; M. S. de Oliveira a partir da 4a Lição). Portugal: Edições 70. (Trabalho original publicado em 1968)

Costa, J. F (1989). Narcisismo em tempos sombrios. In. H. R. Fernandes (Org.), Tempo do desejo: sociologia e psicanálise (pp. 109-136). São Paulo: Brasiliense.

Crochík, J. L. (1990). O ajustamento do pensamento em uma sociedade de alto desenvolvimento tecnológico: o computador no ensino. Tese de Doutorado, Instituto de Psicologia, Universidade de São Paulo, São Paulo.

Crochík, J. L. (1999). A ideologia da racionalidade tecnológica e a personalidade narcisista. Tese de livre-docência, Universidade de São Paulo, São Paulo.

Crochík, J. L. (2000a). Ulisses e Narciso: o abandono de si mesmo e o abandono a si mesmo. Olhar - Centro de Educação e Ciências Humanas da Universidade Federal de São Carlos, 2(4), 19-37.

Crochík, J. L. (2000b). Tecnologia e individualismo: um estudo de uma das relações contemporâneas entre ideologia e personalidade. Análise Psicológica, 18(4), 529543.

Crochík, J. L. (2001). A formação do indivíduo e a dialética do esclarecimento. Nuances. Revista do Curso de Pedagogia. Faculdade de Ciências e Tecnologia, 7(7), 1-9.

Crochík, J. L. (2003a). O desencanto sedutor: a ideologia da racionalidade tecnológica. Interação. Revista da Faculdade de Educação da UFG, 28(1), 15-35.

Crochík, J. L. (2003b). Teoria crítica e novas tecnologias da educação. In B. Pucci et al. (Org.), Tecnologia, cultura e formação - ainda Auschwitz (pp. 97-114). São Paulo: Cortez. 
Crochík, J. L. (2004). A normalidade do sofrimento. Manifesto - Revista mensal da oficina de informações, 5(61), 42-43.

Freud, S. (1974a). Luto e melancolia. In S. Freud, Edição standard brasileira das obras psicológicas completas de Sigmund Freud (J. Salomão, trad., Vol. 14, pp. 269-291). Rio de Janeiro: Imago. (Trabalho original publicado em 1917)

Freud, S. (1974b). O humor. In S. Freud, Edição standard brasileira das obras psicológicas completas de Sigmund Freud (J. Salomão, trad., Vol. 21, pp. 187-194). Rio de Janeiro: Imago. (Trabalho original publicado em 1927).

Freud, S. (1974c). Sobre o narcisismo: uma introdução. In S. Freud, Edição standard brasileira das obras psicológicas completas de Sigmund Freud (J. Salomão, trad., Vol. 14, pp. 83-119). Rio de Janeiro: Imago. (Trabalho original publicado em 1914).

Freud, S. (1976a). Psicologia de grupo e a análise do ego. In S. Freud, Edição standard brasileira das obras psicológicas completas de Sigmund Freud (J. Salomão, trad., Vol. 18, pp. 87-179). Rio de Janeiro: Imago. (Trabalho original publicado em 1921)

Freud, S. (1976b). Inibições, sintomas e ansiedade In S. Freud, Edição standard brasileira das obras psicológicas completas de Sigmund Freud (J. Salomão, trad., Vol. 20, pp. 93-201). Rio de Janeiro: Imago. (Trabalho original publicado em 1926)

Freud, S. (1976c). Teoria geral das neuroses. Conferência XXVI - A teoria da libido e o narcisismo. In S. Freud, Edição standard brasileira das obras psicológicas completas de Sigmund Freud (J. Salomão, trad., Vol. 16, pp. 481-502). Rio de Janeiro: Imago. (Trabalho original publicado em 1917)

Freud, S. (1976d). Neurose e psicose. In S. Freud, Edição standard brasileira das obras psicológicas completas de Sigmund Freud (J. Salomão, trad., Vol. 19, pp. 185-224). Rio de Janeiro: Imago. (Trabalho original publicado em 1924).

Freud, S. (1976e). O ego e o id. In S. Freud, Edição standard brasileira das obras psicológicas completas de Sigmund Freud (J. Salomão, trad., Vol. 19, pp. 11-83). Rio de Janeiro: Imago. (Trabalho original publicado em 1923)

Hassoun, J. (2002). A crueldade melancólica (R. Aguiar, trad.). Rio de Janeiro: Civilização Brasileira. (Trabalho original publicado em 1995)

Horkheimer, M. (2000). Eclípse da razão. São Paulo: Centauro. (Trabalho original publicado em 1946)

Horkheimer, M., \& Adorno, T. W. (1985). Ulisses ou mito e esclarecimento. In M. Horkheimer \& T. W. Adorno, Dialética do esclarecimento: fragmentos filosóficos (G. A. de Almeida, trad., pp. 53-80). Rio de Janeiro: Jorge Zahar. (Trabalho original publicado em 1947)

Horkheimer, M., \& Adorno, T. W. (1985). A indústria cultural: o esclarecimento como mistificação das massas. In M. Horkheimer \& T. W. Adorno, Dialética do esclarecimento: fragmentos filosóficos (G. A. de Almeida, trad., pp. 113-156). Rio de Janeiro: Jorge Zahar. (Trabalho original publicado em 1947)

Horkheimer, M., \& Adorno, T. W. (1985). Elementos do anti-semitismo: limites do esclarecimento. In M. Horkheimer \& T. W. Adorno, Dialética do esclarecimento: fragmentos filosóficos (G. A. de Almeida, trad., pp. 157-194). Rio de Janeiro: Jorge Zahar. (Trabalho original publicado em 1947) 
Horkheimer, M., \& Adorno, T. W. (1973). A massa. In M. Horkheimer \& T. W. Adorno (Orgs.), Temas básicos da sociologia (A. Cabral, trad., pp. 78-92). São Paulo: Cultrix. (Trabalho original publicado em 1956)

Marcuse, H. (1967). A ideologia da sociedade industrial (G. Rebuá, trad.). Rio de Janeiro: Zahar. (Trabalho original publicado em 1964)

Marcuse, H. (1998). A obsolescência da psicanálise. In H. Marcuse, Cultura e sociedade (I. M. Loureiro, trad., Vol. 2, pp. 91-111). Rio de Janeiro: Paz e Terra. (Trabalho original publicado em 1963)

Marcuse, H. (1999a). Algumas implicações sociais da tecnologia moderna. In H. Marcuse, Tecnologia, guerra e fascismo (M. C. V. Borba, trad., pp. 71-104). São Paulo: Fundação Editora da UNESP. (Trabalho original publicado em 1941)

Marcuse, H. (1999b). Eros e civilização: uma interpretação filosófica do pensamento de Freud (A. Cabral, trad., 8a ed.). Rio de Janeiro: LTC. (Trabalho original publicado em 1955)

Pedrossian, D. R. S. (2005). A ideologia da racionalidade tecnológica, o narcisismo e a melancolia: marcas do sofrimento. Tese de Doutorado, Pontifícia Universidade Católica de São Paulo, São Paulo.

Tiburi, M. (1995). Crítica da razão e mímesis no pensamento de Theodor W. Adorno. Porto Alegre: EDIPUCRS.

Dulce Regina dos Santos Pedrossian, Psicóloga Doutora do Departamento de Ciências Humanas do Centro de Ciências Humanas e Sociais da Universidade Federal de Mato Grosso do Sul - UFMS e Professora Colaboradora de Cursos de Graduação da UFMS. Av. Afonso Pena, 3103, apto. 301 Campo Grande - MS. CEP 79.002-072. Endereço eletrônico:drsp@terra.com.br

Recebido em: 25/07/2006

Aceito em: $9 / 06 / 2008$ 